\title{
The Impact of Covid-19 on Food Security A quantitative analysis of the rise in London's existing food insecurity due to the financial impact of Covid-19
}

\author{
Leandra Geyser \\ leandra.geyser@outlook.com
}

\section{Abstract}

Background: The lockdown, enforced by government to limit the spread of Covid-19, has resulted in economic standstill equating to decreased working hours, pay cuts and job losses which has caused an increase in food insecurity. In the latest global food security report, 3.4 million people in the UK alone were found to be moderately to

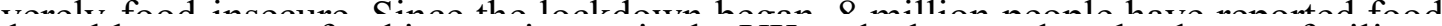
vulnerable groups to food insecurity are in the UK and what needs to be done to facilitate positive change and minimise future inequalities. Methods: This observational quantitative study makes use of the Understanding Society Covid-19 survey data which forms part of a longstanding longitudinal study that has acted as a representative of all households within the UK since 2009. Access to raw data was granted by the UK Data Service and was analysed using the appropriate SPSS tests. The original sample was stratified to be representative of London, which then consisted of 1849 respondents. Selected questions relating to financial and food bank use were analysed using SPSS and compared between February (pre-lockdown) and April (postlockdown).

Results: Black, Asian and Minority Ethnic (BAME) respondents and those not born in the UK had significantly less monthly income than their counterparts in February and remained significantly lower during the lockdown. These groups also had an increased dependency on foodbanks since the start of the pandemic.

Conclusion: BAME communities and those not born in the UK are revealed to be the most vulnerable groups to food insecurity. The government has taken steps to mitigate the negative financial impact of the pandemic for some, yet many had to rely on nongovernmental organisations (NGOs) to fill in the gaps. The current health crisis provides an opportunity for change and the UK government should act now to prevent many more becoming victims to food insecurity.

Keywords: Covid-19, coronavirus, food insecurity, London, BAME, household food security, nutrition, migrants, United Kingdom, UK born. 


\section{Introduction}

The novel coronavirus, a contagious viral infection which causes Covid-19, was first reported to be spreading among the Chinese population of Wuhan towards the end of December 2019. It has a detrimental effect on the human respiratory system, which can lead to severe acute respiratory syndrome in vulnerable groups. These groups include those who are elderly, obese and have other pre-existing health conditions such as hypertension and diabetes (Kannan et al., 2020). The World Health Organisation [WHO] officially declared it a worldwide pandemic on the $11^{\text {th }}$ of March 2020. Trying to limit the devastating loss of life and pressure on healthcare systems, the UK introduced several restrictions on work and travel on the $23^{\text {rd }}$ of March 2020 (here referred to as lockdown), which posed a significant threat to many livelihoods across the country (Neitzel and Vargas, 2020; Zhang and Liu, 2020).

As stated at the World Food Summit in 1996, "food security exists when all people, at all times, have physical and economic access to sufficient, safe and nutritious food to meet their dietary needs and food preferences for an active and healthy life" (WFS, 1996). In 2019, 690 million people around the world were found to be undernourished, with the pandemic expected to increase this number by at least 60 million (FAO, 2020, p 8). It is a common misconception that food insecurity is only the fate of those that are extremely poor, living in developing countries far away from the developed world, where food is plentiful. However, in the latest global food security report, 3.4 million people in the UK were found to be moderately to severely food insecure (FAO, 2019; FAO, 2020). According to a UNICEF report, the UK was the worst performer for severe childhood food insecurity when compared to the rest of Europe, at $10.4 \%$, despite having the $5^{\text {th }}$ strongest economy in the world (UNICEF, 2017). The most common area of concern in a developed setting is household and individual food insecurity which are predominantly caused by financial difficulties concerned with the affordability of food (Pérez-Escamilla and Segall-Corrêa, 2008). The UK is dependent on global food availability due to importing over $50 \%$ of its produce. Food prices are very sensitive to disruptions to the food system which will not only be affected by the pandemic, but the consequences of what Brexit will bring, all of which is predicted to increase the cost of food and as such may exacerbate existing food insecurities (Defra 2017; Resource trade, 2018).

Links have been made between austerity and an increase in reliance on non- governmental organisations (NGOs) for food (Lambie-Mumford and Sims, 2018). Following the financial crash of 2008 and the appointment of the coalition government in 2010, a new benefit system was adopted, and local authorities saw budget cuts of up to $49 \%$ (Arie, 2018). Stuckler et al. (2017) report that these austerity measures disproportionately affect those most vulnerable to food insecurity. Faced with a reduction in income, the food budget is often the most expendable, as other costs such as rent remain fixed. As seen in Figure 1, since the roll out of universal credit in 2013: the UK's latest unemployment benefit system, there was a subsequent rise in foodbank dependency which might be indicative of its failure to support those vulnerable to food insecurity (Trussell Trust, 2019).

London is one of the richest cities in the world, yet it is also home to the highest levels of poverty in the UK. The capital has around 9 million inhabitants, of which over 2 million people live in poverty. This is due to low wages and high living, transportation, and childcare costs (Trust for London, 2018). 
Figure 1. Rise of foodbank use since the roll-out of universal credit (Trussell Trust, 2019).

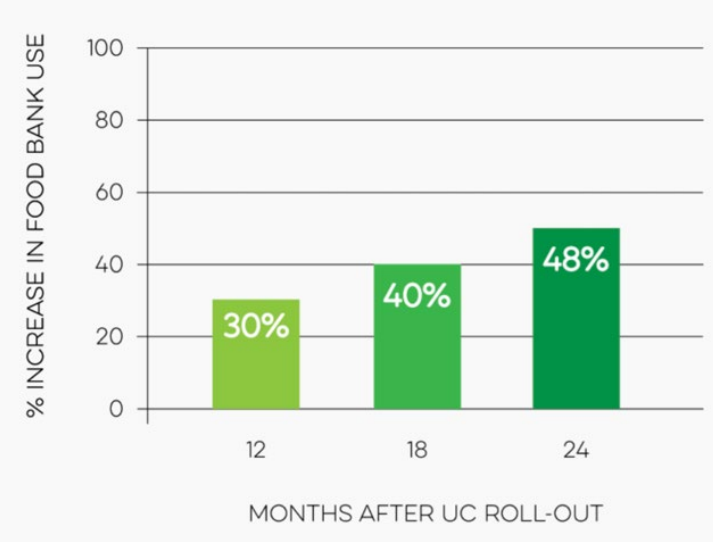

Furthermore, over 3.3 million people consist of non-UK born migrants. UK immigration has been rapidly increasing, with around 5 million in 2004 to over 9 million in 2019 (Rienzo and Vargas-Silva, 2020).

Living expenses are rising faster than the inflation rate, meaning that in comparison to a rise of $2.1 \%$ in the national living wage, the cost of other expenses such as council tax, heating and transportation increases by as much as $3.6 \%$. Since the start of the pandemic there has been an increased need for universal credit, as many face unemployment or are unable to survive on a reduced income (Hirsch, 2020). In the latest quarterly report from the Department of Work and Pensions (DWP), as seen in Figure 2, 4.2 million people were due to be receiving universal credit at the start of April, which is an increase of $40 \%$ since lockdown started in March. This is a stark contrast to the expected $4 \%$ month-on-month increase, indicating a rapid rise in unemployment and as such posing a greater risk to food insecurity, especially since there is a 5-week wait from registration till the initial payment is received (DWP, 2020). This was confirmed by a rapid food security assessment rolled out by The Food Foundation, which found that 8 million people were reporting food insecurity at the start of April in 2020 (Loopstra, 2020).

Figure 2. The number of people receiving universal credit (DWP, 2020).

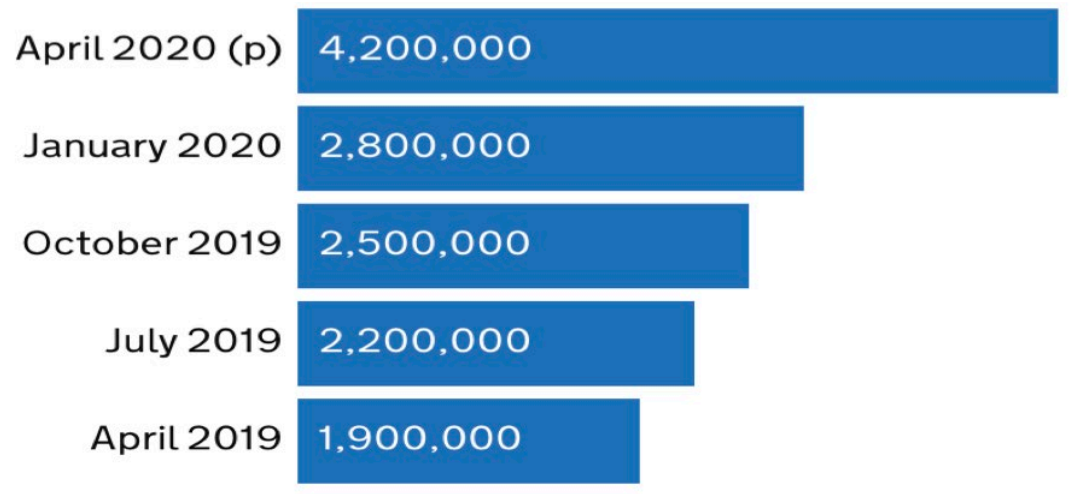

(p) = Partial representation, recorded on the 9th of April 2020 
On average, NGOs reported a 44\% increase in those seeking support in the form of food provisions since the start of lockdown. According to a recent Trussell Trust report, compared to April 2019, foodbank use has increased by $89 \%$ in April 2020. At the start of the lockdown, foodbanks saw an $81 \%$ increase in just 2 weeks. The number of children now reliant on foodbanks has increased by $107 \%$ compared to this time last year. This indicates that need is outweighing the help available. (Trussell Trust, 2020).

Since the start of the pandemic, it became clear that Covid-19 was disproportionately affecting those from ethnic minorities. A House of Lords' (2020) report confirmed that those of Black, Asian and Minority Ethnic (BAME) backgrounds were between twice to eight times more likely to die of Covid-19 compared to Caucasian individuals. In-depth qualitative analyses suggested that the reasons were housing, increased occupational risk due to being keyworkers, socio-economic status, and other social and structural risks putting them at a daily disadvantage, not just to Covid-19 but to other health inequalities including Non-Communicable Diseases [NCDs] (DWP, 2020, Gumber and Gumber, 2017). According to a report by Lang et al. (2018) low-income earners face financial pressure when attempting to access healthy and nutritious food. This is supported by Scarborough et al. (2018) who found that one would need $£ 41.93$ per person per week to be able to afford the 2018 'Eatwell Guide' as recommended by the Department of Health (see Figure 3). Yet benefit payments in 2018 equated to $£ 57.90$ per week. Cheap food, high in fat and sugar, is thus contributing to the high burden of NCDs among low-income groups, especially ethnic minorities (DWP, 2019; PHE, 2018).

Figure 3. The UK's Eatwell Guide (PHE, 2018).

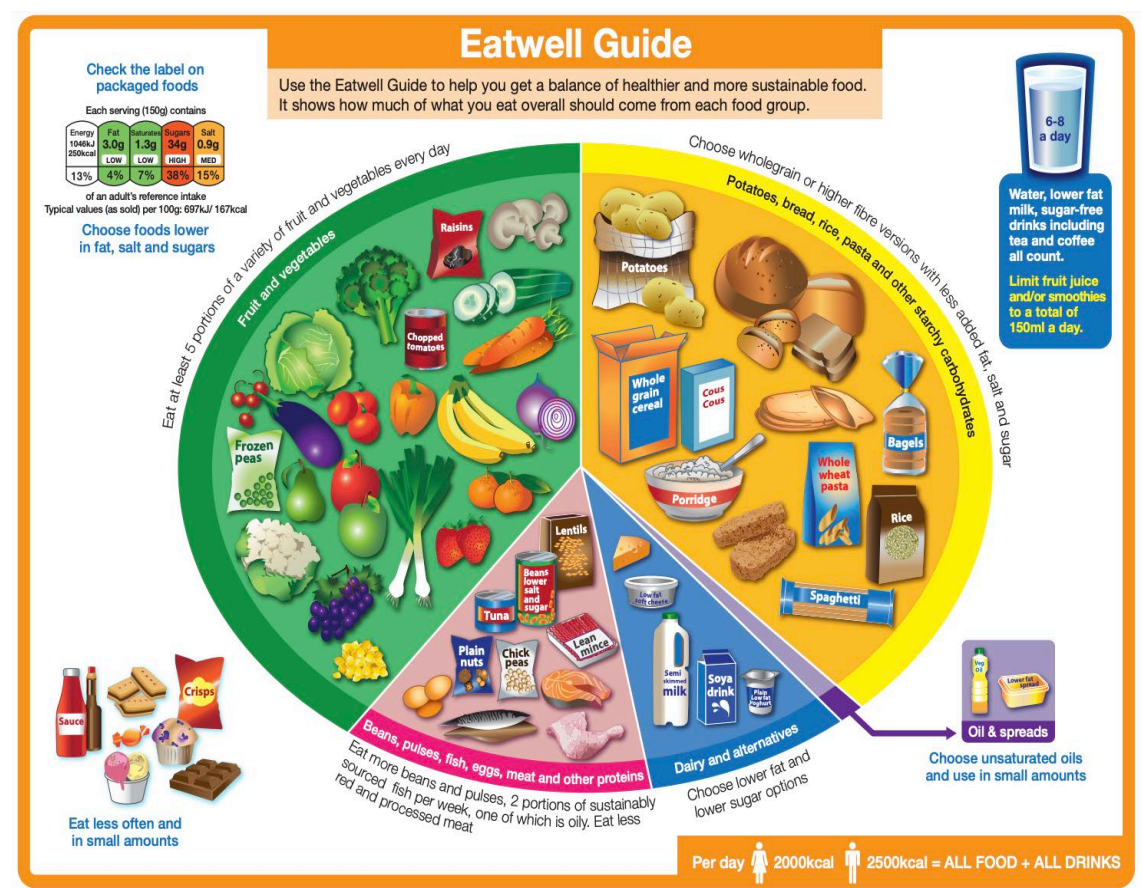

The UK government, trying to mitigate for the threat to livelihoods that Covid-19 has introduced, launched a coronavirus job retention scheme to ensure that $80 \%$ of wages will be received by those already in employment yet are unable to work. Although this financial support given by government was welcome, many were falling through the 
cracks of these efforts, forcing low-income families that were either not benefiting from the furlough scheme or not able to get by with a $20 \%$ loss in income, into destitution (Ahmed et al., 2020). Other government initiatives, such as offering free school meal vouchers during school closures has offered much needed support to those who are eligible, sadly those with no recourse to public funding, such as migrants, are often excluded from such relief packages. When this was addressed, after some persistent lobbying from NGOs, the free school meal vouchers were extended to include those who would usually not be eligible, yet still excluded many due to imposing strict thresholds for eligibility. This threshold, which was set at $£ 616$ per month, was far below a realistic living wage and would not cover basic living costs in London (Hirsch, 2020; Trust for London, 2019).

As the repercussions of the Covid-19 pandemic is yet to be determined, not a lot of data exist around its impact on food security. The main objectives of the study include first identifying the indicators that will determine the impact of Covid-19 on food security in London and then determining who is most at risk of household food insecurity.

\section{Study Design and Methods of Data Analysis}

Access to the raw Understanding Society Covid-19 survey data, which has acted as a representative of all households within the UK since 2009, was granted by the UK Data Service (Institute for Social and Economic Research, 2020).

The original sample was stratified to be representative of London, which consisted of 1849 respondents. The selected groups were categorised by ethnicity (BAME and nonBAME) and country of birth (born in the UK or not born in the UK). Selected questions from the original survey relating to monthly income and food bank use acted as proxy indicators of food insecurity and were analysed using SPSS (IBM Corp, 2017). To indicate the impact of the Covid-19 pandemic, monthly income of February (prelockdown) was compared with that of April (post-lockdown).

All Understanding Society samples are probability samples of household addresses. Samples from England, Scotland and Wales were clustered systematic random samples, and the data were weighted appropriately to allow for a population inference (Benzeval et al., 2020). Of the 42330 participants who were invited to participate in the survey, there were 17452 respondents. Invitations to take part in the original survey were sent out by text, email or by post to previous Understanding Society survey respondents on the 24th of April 2020. Each survey took an average of 20 minutes to complete (Institute for Social and Economic Research, 2020).

A related-samples Wilcoxon signed-rank test was performed for the repeated measures of monthly earnings reported for February and April. A negative $\mathrm{Z}$ score indicates that the $2^{\text {nd }}$ measurement taken in April is less than the measurement taken in February. To test for the association between categorical variables a Chi-squared $\left[x^{2}\right]$ test was performed to determine foodbank use (Agresti, 2018). 


\section{Results}

$45 \%$ of the sample; representative of London, were BAME respondents $(n=1781)$ and $33 \%$ were not born in the UK $(n=1793)$. This reveals that both BAME respondents and those not born in the UK made up the minority when compared to non-BAME respondents and those born in the $\mathrm{UK}$, respectively. BAME respondents $(\mathrm{Z}=-6.087, \mathrm{p}=<$ $.001)$ and those not born in the UK $(Z=-4.260, p=<.001)$ had significantly less monthly income than their counterparts in February and remained significantly lower in April. However, the decline was approximately equal in both groups.

Of all those that said yes to foodbank use, BAME respondents were significantly more dependent on foodbanks than their counterparts $\left(x^{2}=11.21, \mathrm{p}=.004, \mathrm{~N}=1608\right)$. Those not born in the UK, were twice as likely to make use of foodbanks than those born in the UK $\left(x^{2}=6.16, \mathrm{p}=.062, \mathrm{~N}=1619\right)$.

\section{Discussion}

Even though most people experienced a significant reduction in income due to the consequences of the Covid-19 pandemic, for BAME respondents (Figure 4) and those not born in the UK (Figure 5), earnings were significantly less than those of their counterparts both before and after the lockdown. This speaks to existing inequalities, putting these groups at an increased risk to responding negatively to the health and financial shocks of Covid-19 as well as exacerbating food insecurities (DWP, 2020).

During the lockdown, many could not afford a $20 \%$ reduction in their monthly income and others lost their jobs. Those that are most vulnerable to financial shock, and as such food insecurity, are those who were already struggling before the pandemic hit and are now forced to rely on overwhelmed NGOs for support.

Power et al. (2018) found that food insecurity is highly associated with socio-economic status and Huang et al. (2018) found food insecurity more prevalent among particularly vulnerable households such as low-income families and those of racial minorities. The equal decline in income across all groups, seen in both Figure 4 and 5, is indicative of the detrimental impact that Covid-19 has had on everyone irrespective of their initial financial status. Loopstra (2020) found that affordability but also access to food were the main contributing factors to the rise in food insecurity in the UK at the start of the lockdown. The pandemic shines an uncomfortable light on these inequalities that are by no means new but exacerbate truths that can no longer be ignored.

Furthermore, the Trussell Trust reported an 89\% increase in foodbank use in April 2020 compared to the same period last year (Trussell Trust, 2020). Those from BAME backgrounds were over 4 times more likely to make use of foodbanks, and although this was not statistically significant, those not born in the UK were twice as likely to make use of foodbanks. This is supported by the Food Foundation, who found BAME respondents twice as likely to be food insecure (Loopstra, 2020). It should be noted that $70 \%$ of those not born in the UK identify as BAME, therefore there is expected to be some overlap within these findings (DWP, 2020; Gumber and Gumber, 2017). 
Figure 4. Changes in pre- and post-lockdown monthly earnings between BAME and non-BAME respondents.

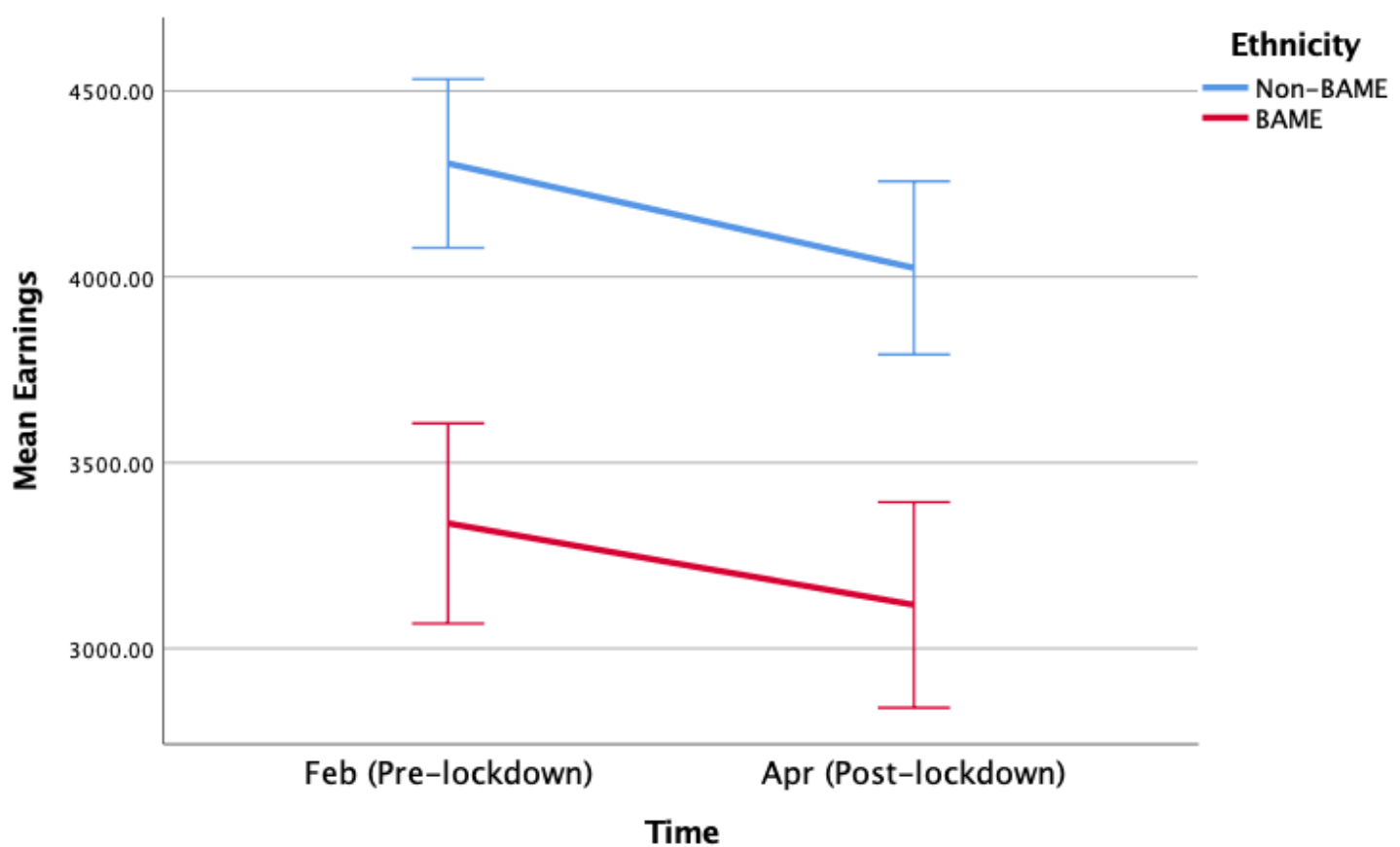

Figure 5. Changes in pre- and post-lockdown monthly earnings between those born in the UK and those not born in the UK.

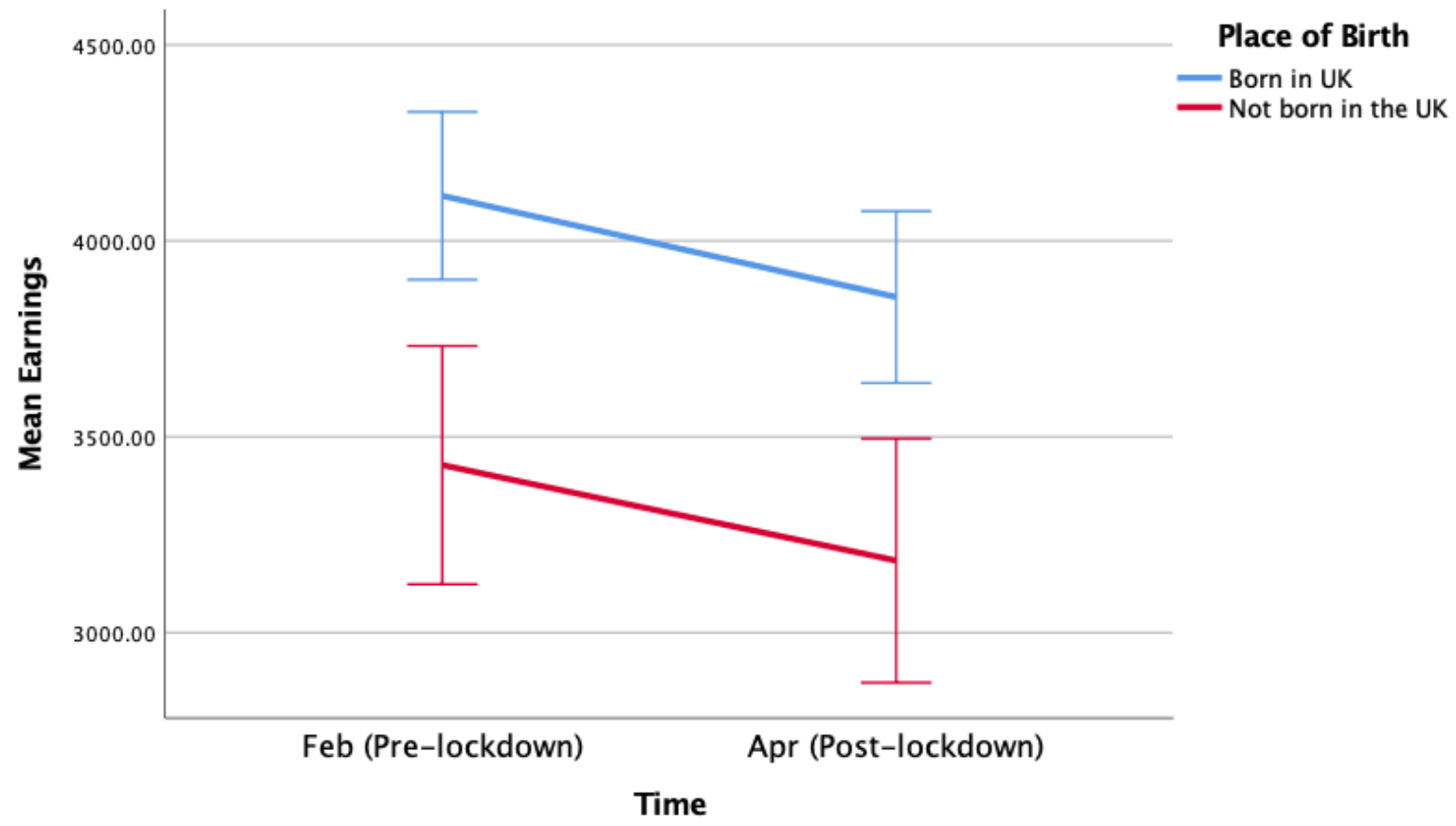




\section{Limitations}

None of the data sets were found to be normally distributed; however according to Ghasemi and Zahediasl (2012), the standard tests for normality, Kolmogorov-Smirnov and Shapiro-Wilk test, have been found to be too sensitive for large data sets. As it was necessary to determine whether the sample data showed a serious deviation from normality, and due to these tests having few alternatives they were used to test for normal distribution (Elliott and Woodward, 2007).

Many of the statistically significant results show small effect sizes. This is to be expected with large samples with a high standard deviation, as seen in these data (Schäfer and Schwarz, 2019). Additionally, having unbalanced samples sizes is further expected to reduce the effect size, as indicated by Agresti (2018). Varying sample sizes were accounted for by presenting all data as percentages.

\section{Recommendations}

The complex issue of why Covid-19 has been disproportionately affecting BAME communities in the UK is nothing a household survey could not highlight; persistent preexisting societal and ethnic inequalities have been and continue to be the epicentre of health disparities. The Covid-19 pandemic is highlighting existing inequalities that require urgent action from government. It is utterly unthinkable that this should be a reality in one of the world's strongest economies and richest global cities. That being said, the pandemic provides an opportunity for change and acts as a wake-up call, a chance for taking action so those most vulnerable are protected from destitution in future.

The implementation of the following action points by government is needed to ensure that people facing food insecurity do not have to rely on NGOs, some of which have been completely overwhelmed during this pandemic.

\section{Tackling food insecurity}

The UK requires their own measure of food insecurity. A report on the findings of the pilot governmental measure of food insecurity in the UK is expected to be released in 2021. Measuring food insecurity should be prioritised as well as implementing the following:

- Investigate what compromises on dietary quality exist due to lack of sufficient income.

- Revise the eligibility criteria and reduce the 5-week wait for the initial Universal Credit payment.

- Those with no recourse to public funding require new legislation that protects them from destitution.

- The benefit threshold, due to be reviewed in 2021, should be inclusive of the funds needed to sustain a healthy diet and at the very least aim to cover the 'Eatwell Guide' diet for each individual in the household.

- An increase that matches inflation to food prices should be applied to all governmental support 


\section{Tackling inequality}

Whilst the changes highlighted above would go a long way in levelling out existing inequalities, it is advised that government use the results of countless research highlighting the socio-economic determinants of inequality to facilitate infrastructural changes needed to address ethnic disparities.

\section{References}

Agresti A. 2018. An introduction to categorical data analysis. John Wiley \& Sons, New Jersey.

Ahmed F, Ahmed N, Pissarides C, et al. 2020. Why inequality could spread COVID-19. The Lancet Public Health 5(5):e240 http://dx.doi.org/10.1016/S2468-2667(20)30085-2

Arie S. 2018. Austerity in the UK: rising poverty threatens stability and health. BMJ: British Medical Journal 363:k4897 doi: https://doi.org/10.1136/bmj.k4897

Benzeval M, Burton J, Crossley T. 2020. Understanding Society COVID-19 Survey, April Briefing Note: The Economic Effects, Working Paper No 10/2020, ISER, University of Essex.

DEFRA Department of Environment, Food and Rural Affairs. 2017. National Statistics: Food statistics in your pocket. Global and UK supply. London: DEFRA.

https://www.gov.uk/government/publications/food-statistics-pocketbook-2017/food-statisticsin-your-pocket-2017-global-and-uk-supply

DWP: Department for Work and Pensions. 2019. Policy paper: Benefit and pension rates 2019 to 2020. DWP, London. https://www.gov.uk/government/publications/benefit-and-pensionrates-2019-to-2020/proposed-benefit-and-pension-rates-2019-to-2020

DWP: Department for Work and Pensions. 2020. Official Statistics: Universal Credit: 29 April 2013 to 9 April 2020. https://www.gov.uk/government/publications/universal-credit-29-april2013-to-9-april-2020/universal-credit-29-april-2013-to-9-april-2020\#things-you-need-to-know

Elliott AC, and Woodward WA. 2007. Statistical analysis quick reference guidebook: With SPSS examples. Sage.

FAO, IFAD, UNICEF, WFP and WHO. 2019. The State of Food Security and Nutrition in the World 2019. Safeguarding against economic slowdowns and downturns. Rome, FAO. https://docs.wfp.org/api/documents/WFP$\underline{0000106760 / \text { download/? ga }=2.39677667 .116299562 .1588003720-328599407.1583846502}$

FAO, IFAD, UNICEF, WFP and WHO. 2020. The State of Food Security and Nutrition in the World 2020. Transforming food systems for affordable healthy diets. Rome, FAO. http://www.fao.org/documents/card/en/c/ca9692en

Ghasemi A, and Zahediasl S. 2012. Normality tests for statistical analysis: a guide for nonstatisticians. International Journal of Endocrinology and Metabolism 10(2):486.

Gumber A, and Gumber L. 2017. Improving prevention, monitoring and management of diabetes among ethnic minorities: contextualizing the six G's approach. BioMed Central Research Notes 10(1):1-5. 
Hirsch D. 2020. A Minimum Income Standard for the United Kingdom in 2019. Joseph

Rowntree Foundation, York. https://www.jrf.org.uk/report/minimum-income-standard-uk-2019

House of Lords. 2020. Hungry for Change: Fixing the Failures in Food. Select Committee on Food, Poverty, Health and the Environment. Report of Session 2019-20.

Huang X, and King C. 2018. Food insecurity transitions and housing hardships: Are immigrant families more vulnerable? Journal of Urban Affairs 40(8):1146-1160.

IBM Corp. 2017. IBM SPSS Statistics for Mac, Version 25.0. Armonk, NY: IBM Corp.

Institute for Social and Economic Research. 2020. Understanding Society COVID-19 User Guide. Version 1.0, May 2020. Colchester: University of Essex.

Kannan S, Ali PSS, Sheeza A, et al. 2020. COVID-19 (Novel Coronavirus 2019)-recent trends. Eur. Rev. Med. Pharmacol. Sci. 24(4):2006-2011.

Lambie-Mumford H, Sims L. 2018. 'Feeding hungry children': the growth of charitable breakfast clubs and holiday hunger projects in the UK. Children \& Society 32(3):244-54.

Lang T, Lewis T, Marsden T, and Millstone E. 2018. Feeding Britain: food security after Brexit. London, UK: Food Research Collaboration.

Loopstra R. 2020. Vulnerability to food insecurity since the COVID-19 lockdown. London: The Food Foundation. https://foodfoundation.org.uk/wp-content/uploads /2020/04/Report_Covid19FoodInsecurity-final.pdf

Neitzel J, Vargas M. 2020. Mitigating the effects of the COVID-19 pandemic on food and nutrition of schoolchildren. Rome: WFP: World Food Programme; FAO: Food and Agriculture Organization of the United Nations; UNICEF: United Nations International Children's Emergency Fund.

https://www.unicef.org/laos/media/3456/file/Mitigating $\% 20$ the $\% 20$ effects $\% 20$ of $\% 20$ the $\% 20 \mathrm{C}$ OVID-19\%20pandemic $\% 20 . p d f$

Pérez-Escamilla R, and Segall-Corrêa AM. 2008. Food insecurity measurement and indicators. Revista de Nutrição 21:15-26. http://www.scielo.br/scielo.php?script=sci_arttext\&pid=S141552732008000700003\&lng=en\&tlng=en

PHE: Public Health England. 2018. The Eatwell Guide: Helping you eat a healthy, balanced diet. London, PHE.

https://assets.publishing.service.gov.uk/government/uploads/system/uploads/attachment data/fil e/742750/Eatwell_Guide booklet_2018v4.pdf

Power M, Uphoff EP, Stewart-Knox B, et al. 2018. Food insecurity and socio-demographic characteristics in two UK ethnic groups: an analysis of women in the Born in Bradford cohort. Journal of Public Health 40(1):32-40.

Resource Trade. 2018. United Kingdom. Chatham House: The Royal Institute of International Affairs. https://resourcetrade.earth/data? year=2018\&importer=826\&units=value

Rienzo C, and Vargas-Silva C. 2020. Migrants in the UK: An Overview. Migration Observatory briefing, COMPAS, University of Oxford. 
Scarborough P, Kaur A, Cobiac L, et al. 2016. Eatwell Guide: modelling the dietary and cost implications of incorporating new sugar and fibre guidelines, British Medical Journal 6:e013182. doi: 10.1136/bmjopen-2016-013182

Schäfer T, and Schwarz MA. 2019. The meaningfulness of effect sizes in psychological research: Differences between sub-disciplines and the impact of potential biases. Frontiers in Psychology 10:813.

Stuckler D, Reeves A, Loopstra R, et al. 2017. Austerity and health: the impact in the UK and Europe. European Journal of Public Health 27(4):18-21.

Trussell Trust. 2019. Universal credit and foodbanks. https://www.trusselltrust.org/what-wedo/research-advocacy/universal-credit-and-foodbank-use/

Trussell Trust. 2020. Summary findings on the impact of the Covid-19 crisis on foodbanks. https://www.trusselltrust.org/wp-content/uploads/sites/2/2020/06/APRIL-Databriefing_external.pdf

Trust for London. 2018. The age distribution of the population. https://www.trustforlondon.org.uk/data/population-age-groups/

Trust for London. 2019. A Minimum Income Standard for London 2019. https://www.trustforlondon.org.uk/publications/mislondon2019/

UNICEF. 2017. Building the Future: Children and the Sustainable Development Goals in Rich Countries, Innocenti Report Card 14, UNICEF Office of Research - Innocenti, Florence. https://www.unicef-irc.org/publications/pdf/RC14_eng.pdf

WFS: World Food Summit. 1996. Rome Declaration on World Food Security. Rome: WFS. http://www.fao.org/3/w3613e/w3613e00.htm

WHO: World Health Organization. 2021. WHO Coronavirus Disease (COVID-19) Dashboard. Geneva: WHO. https://Covid19.who.int/

Zhang L, and Liu Y. 2020. Potential interventions for novel coronavirus in China: A systematic review. Journal of Medical Virology 92(5):479-490.

https://onlinelibrary.wiley.com/doi/abs/10.1002/jmv.25707 